Perspective

\title{
Assessing Animal Welfare with Behavior: Onward with Caution
}

\author{
Jason V. Watters *, Bethany L. Krebs $(\mathbb{D}$ and Caitlin L. Eschmann
}

check for updates

Citation: Watters, J.V.; Krebs, B.L.; Eschmann, C.L. Assessing Animal Welfare with Behavior: Onward with Caution. J. Zool. Bot. Gard. 2021, 2, 75-87. https://doi.org/10.3390/ jzbg2010006

Academic Editors: Katherine A. Cronin

Received: 6 February 2021

Accepted: 25 February 2021

Published: 3 March 2021

Publisher's Note: MDPI stays neutra with regard to jurisdictional claims in published maps and institutional affiliations.

Copyright: (c) 2021 by the authors. Licensee MDPI, Basel, Switzerland. This article is an open access article distributed under the terms and conditions of the Creative Commons Attribution (CC BY) license (https:// creativecommons.org/licenses/by/ $4.0 /)$.
Wellness and Animal Behavior, San Francisco Zoological Society, San Francisco, CA 94132, USA; BethanyK@sfzoo.org (B.L.K.); CaitlinE@sfzoo.org (C.L.E.)

* Correspondence: JasonW@sfzoo.org

\begin{abstract}
An emphasis on ensuring animal welfare is growing in zoo and aquarium associations around the globe. This has led to a focus on measures of welfare outcomes for individual animals. Observations and interpretations of behavior are the most widely used outcome-based measures of animal welfare. They commonly serve as a diagnostic tool from which practitioners make animal welfare decisions and suggest treatments, yet errors in data collection and interpretation can lead to the potential for misdiagnosis. We describe the perils of incorrect welfare diagnoses and common mistakes in applying behavior-based tools. The missteps that can be made in behavioral assessment include mismatches between definitions of animal welfare and collected data, lack of alternative explanations, faulty logic, behavior interpreted out of context, murky assumptions, lack of behavior definitions, and poor justification for assigning a welfare value to a specific behavior. Misdiagnosing the welfare state of an animal has negative consequences. These include continued poor welfare states, inappropriate use of resources, lack of understanding of welfare mechanisms and the perpetuation of the previously mentioned faulty logic throughout the wider scientific community. We provide recommendations for assessing behavior-based welfare tools, and guidance for those developing tools and interpreting data.
\end{abstract}

Keywords: behavioral diagnosis; zoo; behavioral diversity; anticipatory behavior; stereotypy; natural behavior; affect; inductive argument; behavioral context

\section{Introduction}

Accreditation by regional and international zoo and aquarium associations ensures that institutions who display animals to the public practice according to a high standard.

Requirements for these certifications change with advances in practice and internal and external expectations. In accordance with this progression of requirements, the substantial push to emphasize animal welfare by many zoo associations is now well into its second decade. This focus has seen an evolution of the concepts surrounding animal welfare in the zoo and aquarium field [1]. One result of this development is a shift away from solely physical health and natural living concepts of animal welfare towards concepts that include animals' affect. Along with this shift comes a broadening of the vocabulary used to talk about these concepts and includes words like "wellness" that presumably add some sense of animals' own agency to the more static, provisioned concept of welfare. As such, accreditation standards for many associations now include requirements for assessing the welfare of individual animals [2-6]. Essentially, the goal of this sort of criterion is to let the animals "speak for themselves."

As accreditation requirements often do not stipulate how to accomplish welfare assessments, institutions wishing to meet them strive to do so using numerous methods and very typically develop their own tools. For some, scientific approaches seek to determine measures of welfare using integrations of multiple fields. These multi-disciplinary approaches may draw from animal behavior, health, physiology, life history theory, animal husbandry and other fields to reach welfare conclusions based on numerous bits of 
data [7]. Often, multi-disciplinary approaches can become akin to the "all but the kitchen sink" approach to fighting an indomitable adversary and commonly reflect two primary drivers. One is the standing sets of expertise an institution employed prior to the dawn of the welfare movement of zoo and aquarium associations and the accreditation standards it birthed. The second is holistic definitions of welfare that strive to include all factors that might influence animal outcomes but do not describe the conditions under which one discipline's assessment should trump another's [8-10]. While useful, these approaches can also end in disagreement when data from varied disciplines result in disparate interpretations [11]. In other cases, welfare assessors may use an approach that employs a singular primary discipline.

When it comes to singular discipline approaches specific to assessing welfare, animal behavior is most common [12]. This is not to say that animal behavior is paramount. We still do not know the ultimate test for animal welfare. Justification for animal behavior's supremacy as the most-oft employed single discipline welfare assessment is multi-factorial. Historically, the first discipline dedicated to the study of animal welfare was ethology [13]. We can observe animal behavior without special equipment and we often consider behavioral observation to be inexpensive compared to other disciplines. Perhaps also, at the early stages of the development of the discipline, when there was a focus on negative indicators of animal welfare and the goal was to end animal suffering, it was relatively easy to observe when an animal appeared depressed or was performing self-injurious, displaced, or apparently abnormal behaviors. As the focus shifted from negative to positive indicators of welfare [8,9], we have begun to look for signs that animals are able to engage in activities of their own choosing [14-16], and indicators of both momentary and cumulative affective state. Thus, behavioral indication of animal outcomes remains a valuable tool for assessing welfare though the likelihood of miscalculated assessment may be increasing as our understanding of animal welfare becomes more nuanced. What does it matter if our primary tool for "listening to animals," their own behavior, turns out to be a language that we interpret incorrectly? Where are we most likely to go wrong and what are the dangers of getting it wrong?

\section{What Does It Matter If We Get It Wrong?}

When we are not feeling well and go to our physician for help, we hope that we are able to explain our symptoms adequately enough that our doctor is able to diagnose and provide a course of treatment that will promote our return to health. In the event of a misdiagnosis and associated incorrect treatment, there are a few possible outcomes. We can get more ill, we can remain ill, or we can get better for reasons unrelated to the treatment. None of these are positive outcomes. In the case of getting better in spite of the misdiagnosis and incorrect treatment or lack thereof, our doctor can build an erroneous understanding of the problem and how to fix it, putting future patients at risk.

For animal welfare, animal behavior is a diagnostic tool. Practitioners effectively ask what the behavior is telling them about how the animal's environment supports its welfare. Successful diagnosis requires accurate interpretation of what the behaviors observed tell us about welfare outcomes. Like other measuring tools, behavioral observation can capture detail at a fine or a coarse scale. As a blunt example, in many species grooming one's self helps to maintain pelage, keep clean and extract parasites [17]. An observer might interpret this behavior to be one that has positive value towards maintaining coat health. On the other hand, behaviors that appear quite similar to grooming such as self-scratching can be performed under conditions that generate anxiety and are generally interpreted to be indicators of negative affect [18]. We can see that, outside of context, where scratching and grooming are recorded one in place of the other, we can ultimately develop fundamentally different interpretations of the welfare circumstance of the observed animal. If we were unaware of scratching being evidence of anxiety [19] and our interpretation of the function of behaviors that manipulate one's pelage solely related to self-maintenance, we would draw no conclusion regarding circumstances that may be negatively affecting the animal's 
psychological state. We might conclude that the animal is working to get itself clean and that is good, as cleanliness has health benefits. If we use this information to conclude that the animal is handling a manageable problem, in the end, we might do nothing to alleviate the animal's anxiety and may even replicate the conditions that it experiences for other animals. In this case, an inaccurate behavioral assessment would lead to continued compromised welfare for the focal animal, and potentially lead to compromised welfare for other animals receiving similar treatment.

\section{Behavior in Common Concepts of Animal Welfare}

A living animal is always "behaving." Behavior's contexts, precursors and outcomes facilitate our understanding of it. Behavioral assessments focus on the measurement of the outward expression of the presence or absence of animal activity. Only in conjunction with other measures or other information can an assessment tool provide insight to a behavior's cause, outcome, or the feelings associated with its expression. These tools can only address those factors associated with the numerous concepts of animal welfare that can be behaviorally observed and interpreted through regressive, correlative or extrapolative logic.

To appropriately apply behavioral assessments of welfare, it is important to understand several of the most commonly used concepts of animal welfare. As there are numerous tools to measure welfare [20-29], there are also numerous constructs of welfare itself [30]. It is possible for the decision of how to define welfare to reflect one's own philosophical view on animal rights and animal sentience, with each concept leading to a different use of behavioral measures. We discuss challenges for any welfare practitioners adhering to each concept.

\subsection{Physiological Function as Welfare}

A foundational primary construct of welfare considers the proper biological functioning of organisms to be important and generally emphasizes health measures [30,31]. This approach is often used in cases that require welfare assessments of many animals quickly, such as in livestock production. Due to constraints on time and cost, welfare assessors aim to quickly quantify various physiological characteristics such as degree of lameness, presence or absence of lesions, or other measures [7,30-32]. Under this welfare paradigm, an animal would be considered to have adequate welfare if its biological needs are met and it is apparently free from disease [33]. We will not discuss this concept at further length here as it is most commonly assessed with medical and physiological methods and rarely behavior, though behavioral indicators such as lameness and inappetence are often cues for medical workups.

\subsection{Naturalistic Behavior as Welfare}

The natural living concept of animal welfare indicates that animals who are able to perform natural behaviors are in a state of positive welfare. This teleological and logically flawed model has enjoyed favor amongst traditionally anti-anthropomorphic zoo scientists since Hediger's first description of the field zoo biology in the 1950s [34]. It is so thoroughly ingrained in the zoo community that no model of animal welfare can exist in that community without reference to natural behavior. The model has been criticized for numerous reasons but primarily that the performance of natural behavior may not actually reflect positive welfare unless welfare itself is defined as the expression of natural behavior [35-37]. For that reason, the concept can be further criticized as one arisen from circular reasoning. In practice, followers of this model often emphasize the construction of naturalistic looking spaces for animals to live in, perhaps in deference to an assumption that public opinion leans towards this concept of animal welfare and that the public might perceive good welfare from an assessment of the animal's surroundings [38-40]. Additionally, it is not difficult to argue that the majority of the means used to drive "naturalistic behavior" in zoo animals would not be considered as components of a natural environment. Examples here include, but are not limited to, numerous enrichment devices and animal training. 
Naturalistic Behavior-Where Can We Go Wrong?

If one's behavioral concept of animal welfare must include natural behavior, it is relatively straightforward to assess if this goal is met. It is easy to measure behavior in animals under human care and compare that to descriptions of the behavior of animals thought to be living in an undisturbed natural state. Field research has demonstrated that activity budgets within wild populations and groups of the same species can fluctuate with differing environmental conditions [41], resource distribution [42] and varying group size [43], resulting in an added complexity in relying on time budgets as a comparative diagnostic tool [44]. Thus, it is important to determine which natural behavior repertoire one is comparing their animals to and perhaps to justify why other natural behavioral repertoires are, by assumed definition, not the animal welfare goal. Additionally, as in the above example where behavioral repertoires vary with circumstance, it is important to recognize that there is a myriad of covariates that should be recorded [45] as without their measurement, we gain no understanding of the causes of an observed time budget.

\subsection{Affect as Welfare}

Another model describes animals' affect or mood as their welfare state. As the emphasis on affect as welfare continues to grow, many welfare assessors look for behaviors that help them to understand these states. The field has seen growth in observations focusing on specific types of behaviors thought to provide a glimpse into animals' summative affect such as anticipatory behavior [20,46-52] and decision-making behavior [53-56]. There is also a focus on assessing animals' expression of behaviors that may be momentary indicators of positive or negative affect. Among the indicators of positive moments, observers often look for behaviors that indicate that animals are able to express control/agency [15,16,57-59], solve challenges [60-62], investigate [63,64] and express preferences [65-68]. In regard to negative moments, we often look for indicators of anxiety [69,70], fear [68], pain [69,71-74] or boredom [75-77].

\section{Affect-Where Can We Go Wrong?}

There is a danger here of not being guided by theory or empirical work that supports the use of certain behaviors as indicators of affect or directions of valence. There isconsiderable responsibility on the practitioner to ensure that they have developed a cogent, theory driven argument that supports as best as possible an accurate interpretation of the behaviors observed. When considering that an argument is only logically valid if the conclusion follows the premises and that scientific studies generally place some probability on their conclusions, not absolute certainty, we might conclude that there are few, if any, truly validated measures of welfare or affect. Logical premises should support any measure's employment and be clear about the degree of certainty around each premise. The risks associated with misinterpretation warrant clear arguments for the use of any behavioral measure.

\section{Behavioral Measurements of Animal Welfare}

Within any of the common concepts of animal welfare, practitioners can apply a variety of behavioral metrics to assess animal welfare. As with any measurement, the assumptions made prior to collecting data can have implications for what conclusions can be drawn.

\subsection{Behavioral Diversity as an Indicator of Welfare}

In the interest of following the logic, using measures of behavioral diversity as a proxy measure of animal welfare has increased in recent years [10,78-80]. The most commonly used behavioral diversity index, the Shannon-Wiener Diversity index (H-index, [81,82]), is useful for quantifying whether an animal's time budget is heavily skewed towards a few behaviors (low H-index) or spread across multiple behavioral categories (high $\mathrm{H}$ index). The relationship between what the $\mathrm{H}$-index measures and animal welfare is more complicated. The underlying assumption of behavioral diversity as a proxy for welfare 
depends heavily on the natural living model of animal welfare. The tacit assumption is that because animals often display a diverse set of behaviors in the wild, animals in zoos or aquariums should exhibit similarly diverse behavioral repertoires in captivity to have positive welfare. If animal welfare practitioners are moving towards questioning the natural living concept of animal welfare, a similarly critical view of behavioral diversity measures may be warranted.

Cronin and Ross [83] identify several major concerns in the use of this index as a proxy measure for animal welfare. Briefly, the H-index is sensitive to the number of behavioral categories defined by the researcher, sensitive to "lumping" or "splitting" behavioral categories, insensitive to affective valence associated with the behavior, and the interpretation of the index can be impacted by a priori assumptions of researchers (e.g., leaving behaviors with a negative valence out of diversity calculations). The last two points are of particular interest for misdiagnosing or mis-managing animal welfare concerns using this behavioral measure. An increase in diversity overall can include behaviors of positive or negative valence [83]. If the time spent engaged in abnormal repetitive behaviors increased from a low level after an intervention, an individual's diversity measure could increase while the animal experiences a decline in its welfare state. An individual could also have a relatively non-diverse time budget, yet be consistently engaged in positively valenced behaviors (e.g., foraging, play or appropriate conspecific social behaviors). In the first example, misdiagnosing the behavioral change as a net positive would clearly be a miscalculation of the animal's welfare. In the second, the initial conclusion about the animal's state could lead to misguided interventions where none were needed. Excluding negatively valenced or species atypical behaviors from diversity estimates could result in management errors in either direction, as the resulting measure is ignoring an undisclosed amount of the animal's overall time budget. If practitioners only consider "positive" behaviors in the index and do not use the index alongside other measures (e.g., time budget analysis), this effectively limits their ability to "see" negative outcomes. Given the potential risks of misinterpretation leading to suboptimal animal management associated with this behavioral measure, researchers should apply caution (and common sense) when using behavioral diversity as a proxy for animal welfare.

\subsection{Considering Behavioral Context}

Correctly categorizing behavior is the most important component of using it to assess welfare. We have already suggested that assigning a behavior to an inaccurate category (bluntly, good or bad) is an area where we can go wrong when assessing welfare. That there is often some probability that a physical description of behavior can fall into more than one category can increase the chances of sorting behaviors incorrectly. Animals may pace in their enclosure for more than one reason, for example [84]. Cogent arguments that are grounded in the context of the behavior are essential to parse which category a behavior most likely belongs in. Indeed, the use of strong inference [85,86] to help falsify or find support for different hypotheses generated across numerous observations and/or experiments has enjoyed a long history in animal behavior research [87-89]. Providing falsifiable predictions when categorizing behaviors-for example to stereotypy, anxiety, anticipatory behavior or another classification may go a long way in reducing potential mistakes in welfare assessment. It is likely that numerous mis-categorizations of these particular behaviors and others have led to fundamental misunderstanding, ineffective remedies and miscalculation of the welfare state of the cumulative population of zoo animals.

\subsection{Behavioral Repertoires}

Similar to mis-categorizing a given behavior, changes in behavioral repertoires should also be interpreted with caution. In both unpublished and published manuscripts, we have seen authors refer to changes in animals' behavioral time budgets as evidence of either enhanced or decreased welfare. The assessment of these changes is often linked to animals being moved to new exhibits, experiencing new hours where the public is 
allowed into the zoo or modifications to the social group. It is possible to make the mistake of simply assuming that a change in behavioral repertoire indicates a change in animal welfare. However, it is expected that behavior changes should occur in nearly all of these situations - or any situation in which some component of the environment has changed. Behavior is, after all, a primary mechanism for managing environmental change and as such should be extremely sensitive to even subtle environmental modification. Animals change their behavior specifically to adjust their internal state-be it physiological or mood. Thus, change in behavior does not necessarily indicate change in welfare state.

\section{Consequences of Getting It Wrong?}

The outcomes of misapplying behavioral assessments to diagnosing welfare will vary, but can have impacts at multiple levels, from the individual animal to the institution housing the animal to the zoological community and animal welfare science at large. Given the recent focus on animal-centric, individual-based measures of welfare, we are placing implications for the animal's outcomes as the primary concern in this section.

\subsection{Implications for the Animal}

If an animal is wrongly identified as having good welfare when in fact its welfare is compromised, this animal will continue to have compromised welfare. Avoiding such a scenario is a major goal of modern animal welfare science across all animal care settings $[25,29,68,71,90-92]$. Welfare practitioners must be diligent in design of their assessments to avoid falling prey to this error. Much has been written about the necessity of avoiding this particular pitfall, so we will not address this issue at length here (but see $[93,94])$.

If an animal receives an incorrect diagnosis of a welfare issue, interventions may be unwarranted, harmful, or ineffective (Table 1). An intervention would be unwarranted if the animal did not have compromised welfare and was misdiagnosed entirely. If the attempted interventions are minor, such as changes to daily management or enrichment, the interventions may have no effect or a net positive effect on the animal's life though they may modify the animal's behavior extensively. A harmful intervention would lead to a decline in overall welfare. For instance, if an animal were incorrectly identified as having poor welfare when it did not and a major change was prescribed as a solution, such as a significant enclosure modification or a dramatic change to the social group, there could be added discomfort during construction or potential incompatibility with social partners that could lead to a real decline in the individual's welfare. These sorts of modifications may result from a misguided focus on "natural living" opportunities for animals.

Ineffective interventions can lead to the continued persistence of a problem, or to future misapplications of an unfounded intervention if the problem resolves despite the applied mediation. An initially incorrect diagnosis will complicate determining a more effective form of treatment, resulting in potential for continuing compromised welfare for the individual. Perhaps the best result here is that the observer recognizes the ineffectiveness of the treatment and commits further effort to diagnose the underlying issue, ultimately resulting in a net positive outcome for the animal (Table 1). If an animal receives an ineffective treatment and the issue resolves anyway, the animal welfare practitioner may not be aware of the faulty diagnosis and promote inappropriate future applications of the ineffective intervention. 
Table 1. Conceptual relationships between correct or incorrect diagnoses and treatments of welfare issues, their outcomes, broader implications, and their impacts on major stakeholders. Scenarios have been ranked according to the outcome for the animal in question from best to worst. (+) denotes a positive outcome and ( - ) denotes a negative outcome for a particular party. Stakeholders with potentially equivocal outcomes depending on the specific situation have been left out of the final column.

\begin{tabular}{|c|c|c|c|c|}
\hline Diagnosis & Treatment & Outcome & Implications & Impacted Stakeholders \\
\hline Correct & Correct & Problem Resolves & $\begin{array}{l}\text { Appropriate future } \\
\text { treatment }\end{array}$ & $\begin{array}{c}\text { Animal (+) } \\
\text { Institution (+) } \\
\text { Zoological Community }(+) \\
\text { Scientific Community }(+) \\
\text { Animal (+) }\end{array}$ \\
\hline Incorrect & Correct & Problem Resolves & $\begin{array}{l}\text { Inaccurate conclusions about relationship } \\
\text { between diagnosis and treatment }\end{array}$ & $\begin{array}{l}\text { Institution }(-) \\
\text { Zoological Community (-) } \\
\text { Scientific Community }(-)\end{array}$ \\
\hline Correct & Incorrect & $\begin{array}{l}\text { Problem Resolves } \\
\text { (Unrelated to } \\
\text { Treatment) }\end{array}$ & $\begin{array}{l}\text { Inaccurate conclusions about treatment } \\
\text { mechanism }\end{array}$ & $\begin{array}{c}\text { Animal }(+) \\
\text { Institution }(-) \\
\text { Zoological Community }(-) \\
\text { Scientific Community }(-)\end{array}$ \\
\hline Incorrect & Ineffective & $\begin{array}{l}\text { Problem Resolves } \\
\text { (Unrelated to } \\
\text { Treatment) }\end{array}$ & $\begin{array}{c}\text { No knowledge of faulty } \\
\text { diagnosis } \\
\text { Inappropriate application of treatment in } \\
\text { future }\end{array}$ & $\begin{array}{c}\text { Animal }(+) \\
\text { Institution }(-) \\
\text { Zoological Community }(-) \\
\text { Scientific Community }(-)\end{array}$ \\
\hline Incorrect & Unwarranted & $\begin{array}{l}\text { Problem Never } \\
\text { Existed }\end{array}$ & Nothing Happens & $\begin{array}{c}\text { Institution }(-) \\
\text { Zoological Community }(-) \\
\text { Scientific Community }(-)\end{array}$ \\
\hline Correct & Incorrect & Problem Persists & Treatment ineffective & $\begin{array}{l}\text { Animal }(-) \\
\text { Institution }(-)\end{array}$ \\
\hline Incorrect & Ineffective & Problem Persists & $\begin{array}{c}\text { Faulty diagnosis complicates finding } \\
\text { treatments }\end{array}$ & $\begin{array}{c}\text { Animal }(-) \\
\text { Institution }(-)\end{array}$ \\
\hline Incorrect & Harmful & Problem Worsens & $\begin{array}{c}\text { Diagnosis and treatment } \\
\text { re-evaluated }\end{array}$ & $\begin{array}{c}\text { Animal }(-) \\
\text { Institution }(-)\end{array}$ \\
\hline
\end{tabular}

\subsection{Implications for Institutions}

Given the governmental and zoological association oversight in issues of animal welfare, proper diagnosis of animal welfare issues can have serious implications for an institution. Depending on the species of concern and the severity of the issue, institutions may face loss of permits, fines from government agencies, loss of accreditation or membership from zoological associations, or loss of funding opportunities or other resources. For example, in the United States the United States Department of Agriculture (USDA) issues permits to all entities holding or exhibiting wildlife, and retains the right to levy fines or withdraw permits as corrective action against any party not meeting welfare standards [95,96]. Any recipient of a National Science Foundation grant in the United States must abide by the requirements of the Animal Welfare Act to be eligible for funding of research utilizing vertebrate animals [97]. If institutions lose accreditation with the Association of Zoos and Aquariums (AZA), they are no longer eligible to participate in association wide breeding programs or apply for grants available through the association [3]. As such, correct identification of welfare issues must be a cornerstone to any animal welfare program in a modern zoo. The development of a robust animal welfare assessment program is admittedly complicated by various overseeing bodies adhering to different concepts of welfare.

Beyond the potential legal or reputational costs to an institution resulting from misidentification of welfare issues, more serious consequences may involve misallocated resources and perpetuation of inaccurate institutional knowledge. Interventions that are ineffective in solving an issue are a waste of limited resources, unless they are systematically assessed and used to develop an evidence-based understanding of the issue. Often, this is not a goal for institutions with limited resources. In cases where the issue resolves despite an ineffective treatment, institutional knowledge stands to suffer if an incorrect diagnosis 
is paired with a correct treatment, or vice versa. The perceived relationship between the welfare concern and the intervention is incorrect in the first case, and knowledge of the mechanism of action of the treatment is incorrect in the second. Staff sharing knowledge of cases within the institution has implications for the welfare of other animals. Correcting individuals' beliefs of false information is notoriously difficult [98], and as such these types of errors would be particularly challenging for institutions to purge from their informal knowledge base moving forward. Informal knowledge transfer within zoological institutions is an invaluable resource to organizations [99], and due diligence in application of welfare assessments and treatment of welfare concerns can help protect the integrity of aggregate institutional knowledge.

\subsection{Implications for the Zoological Community}

Many of the implications for the zoo and aquarium community at large are similar to implications for individual institutions, but at a larger scale. Continued sharing of incorrect information, whether about diagnoses or treatments of welfare concerns, can have profound implications for the handling of animal welfare issues across the industry. Given the increasing public interest in animal welfare, the collective impact of perpetuating misdiagnoses or incorrect treatment of welfare concerns may ultimately be an erosion in public trust in the expertise of animal welfare practitioners in zoos and aquariums.

\subsection{Implications for Animal Welfare Science}

When research is incomplete in such a way that it does not test alternative hypotheses there is a chance that inaccurate findings can drive practice. In this case, we risk applying proposed remedies with a misunderstanding of mechanism. Therefore, we cannot understand these treatment's efficacy or lack thereof in context. Adjusting them, should they be ineffective, will occur without guidance from an informed understanding of the condition. In addition, we risk developing a body of evidence founded on faulty premises. Development of faulty premises is always a risk when assumptions are based on probabilities. Assuming certainty when it is unproven is a danger to advancing our understanding of any phenomenon, animal welfare being no exception. Consider the case where an observer does not generate falsifiable predictions about possible behavioral categories before classifying a behavior. Only recently have zoo researchers begun to ask if repetitive locomotory activities like pacing are in a different class of behavior from stereotypy, namely anticipatory behavior. Interpretations of these two classes of behavior can be fundamentally different $[52,100]$. If the observer correctly categorizes the behavior, there is little to worry about in terms of application of treatment. However, if they mis-categorize the behavior in such a way that the interpretation of the animal's activity is fundamentally different than if they correctly categorized it, there is substantial danger of setting the stage for long lasting misunderstanding. This can generate a field of study wherein the results of similar research only sometimes agree.

Another potential pitfall can occur when we use evidence gathered under one model of animal welfare to build an assessment tool or treatment for an animal we are monitoring under an alternative construct. For example, Researcher A, who works under the natural living concept of welfare, may find and report that a particular intervention, Treatment A, enhances welfare for their animal. Practitioner B, who ascribes to a primarily affect-based construct of welfare, may find that an animal in their care needs welfare remediation and apply Treatment A to no avail. This sort of mismatch between reported evidence and practical outcome is likely to be common when those reporting outcomes of interventions are not clear about the construct of welfare that they are testing.

\section{Recommendations}

Moving forward we recommend a multi-faceted approach to addressing the outlined concerns associated with behavior-based welfare tools and data interpretation. As a first step, it is imperative to clearly identify the model of welfare the research and/or manage- 
ment changes will utilize and to ensure that the variables measured are appropriate for assessing welfare according to this standard. In other words, is behavior the appropriate construct or does your model of welfare require a different measure, such as physiological or health indicators? Recognizing possible outcomes should be an equally important component of your view of welfare. Ideally your model does not merely require assessing inputs and solely rely on measures such as husbandry practices, enclosure features and social groupings to adequately evaluate an animal's welfare. Every practitioner must first identify these expectations in order to develop a robust assessment tool, especially one that can stand up to scrutiny and be utilized in other institutions. As long as there remains no universally accepted definition or diagnostic tool, it is not enough to simply assume that all practitioner's criteria are comprehensive and equivalent [85]. As established, this is unlikely to be the case, and can result in misinterpretation of affective states and valences, for example, as well as mismanagement of the animals in question.

To avoid such missteps, behaviors used to evaluate animal welfare also must be clearly described and one should always provide context for how and when they are observed. In essence, practitioners should aim to confirm that the behaviors they are using for assessment are in fact "conveying what they think they are conveying". In cases where behaviors are phenotypically similar or even identical but functionally different (e.g., pacing can be stereotypy or anticipatory behavior), the conditions required to place the behavior into one category or another should be described. Similarly, justification for lumping or splitting behavioral categories must be clear and persuasive. Selective exclusion of specific behaviors, whether atypical for the species or negatively valanced, should be avoided. In cases where abnormal behaviors are omitted from $\mathrm{H}$-index calculations, the proportion of time spent expressing those behaviors, and perhaps even an "abnormal H-index", should also be assessed. If assessing affect, whenever possible, there should be falsifiable theory or empirical evidence demonstrating how the behavior relates to the affective state of the individual. In its absence, a cogent inductive argument can be developed that helps to describe conditions under which its conclusions are most probable.

The peer-review process provides a safeguard against the aforementioned pitfalls of misemploying behavioral assessments for welfare diagnosis. Once studies using poorly defined logic make it into the peer-reviewed literature, challenging previously accepted faulty logic becomes an uphill battle. Editors and reviewers need to ensure adequate reporting, with a focus on more methodologically sound papers. Again, this relates back to the importance of clearly defining welfare and the indicators used for assessment of welfare states in the reported study. Journals must ensure that authors not only describe the situation in which the behavior occurs, but also demonstrate that the behavior is assigned to the correct behavioral category and provide best evidence that the observed behavior conveys negative or positive welfare. Without this precise documentation, the interpretation of findings is limited and further citation of the research problematic. It is up to reviewers and editors to hold authors to this higher standard of dissemination.

It is our hope that readers are not discouraged by this message, but rather encouraged to engage in broader, more open and honest conversations and collaborations. In developing your diagnostic tool, the essential question to ask is, "Is my tool designed in such a way as to actually assess what I think I am assessing?" If not, go back and re-evaluate. Assessment tools must be relevant to the practitioner's chosen definition of welfare, and practitioners should avoid using behavioral measures that have only a tangential or equivocal relationship to their definition. Essentially, if your tool does not interpret animals' behaviors to your language, you will not be able to "hear" what they are saying.

Author Contributions: Writing-original draft preparation, review and editing: J.V.W., B.L.K. and C.L.E. All authors have read and agreed to the published version of the manuscript.

Funding: This research received no external funding.

Institutional Review Board Statement: Not applicable. 
Informed Consent Statement: Not applicable.

Data Availability Statement: No new data were created or analyzed in this study. Data sharing is not applicable to this article.

Acknowledgments: We thank our colleague Dave Powell as well as two anonymous peer reviewers for their comments on the manuscript.

Conflicts of Interest: The authors declare no conflict of interest.

\section{References}

1. Powell, D.M.; Watters, J.V. The Evolution of the Animal Welfare Movement in U.S. Zoos and Aquariums. Der Zoöl. Gart. 2017, 86, 219-234. [CrossRef]

2. Mellor, D.; Hunt, S.; Gusset, M. (Eds.) Caring for Wildlife: The World Zoo and Aquarium Animal Welfare Strategy; WAZA Executive Office: Gland, Switzerland, 2015.

3. The Accreditation Standards and Related Policies; Association of Zoos and Aquariums: Silver Spring, MD, USA, 2021.

4. British and Irish Association of Zoos and Aquariums (BIAZA). BIAZA Animal Welfare Policy; BIAZA: London, UK, 2020.

5. European Association of Zoos and Aquaria (EAZA). EAZA Standards for the Accommodation and Care of Animals in Zoos and Aquaria; EAZA: Amsterdam, The Netherlands, 2019.

6. Zoo Aquarium Association Australaia (ZAA). ZAA Accreditation; ZAA: Sydney, Australia, 2021.

7. Johnsen, P.F.; Johannesson, T.; Sandøe, P. Assessment of Farm Animal Welfare at Herd Level: Many Goals, Many Methods. Acta Agric. Scand. Sect. A Anim. Sci. 2001, 51, 26-33. [CrossRef]

8. Mellor, D. Updating Animal Welfare Thinking: Moving beyond the "Five Freedoms" towards "A Life Worth Living". Animals 2016, 6, 21. [CrossRef] [PubMed]

9. Mellor, D.J.; Beausoleil, N.J. Extending the 'Five Domains' model for animal welfare assessment to incorporate positive welfare states. Anim. Welf. 2015, 24, 241-253. [CrossRef]

10. Miller, L.J.; Vicino, G.A.; Sheftel, J.; Lauderdale, L.K. Behavioral Diversity as a Potential Indicator of Positive Animal Welfare. Animals 2020, 10, 1211. [CrossRef]

11. Rushen, J.; de Passille, A.M.B. The scientific basis of animal welfare indicators. In The Assessment and Management of Risks for the Welfare of Production Animals. Food Safety Assurance and Veterinary Public Health; Smulders, F.J.M., Algers, B., Eds.; Wageningen Academic Press: Wageningen, The Netherlands, 2009; Volume 5, pp. 391-416.

12. Binding, S.; Farmer, H.; Krusin, L.; Cronin, K. Status of animal welfare research in zoos and aquariums: Where are we, where to next? J. Zoo Aquar. Res. 2020, 8, 166-174. [CrossRef]

13. Marchant-Forde, J.N. The Science of Animal Behavior and Welfare: Challenges, Opportunities, and Global Perspective. Front. Vet. Sci. 2015, 2, 16. [CrossRef]

14. Bassett, L.; Buchanan-Smith, H.M. Effects of predictability on the welfare of captive animals. Appl. Anim. Behav. Sci. 2007, 102, 223-245. [CrossRef]

15. Buchanan-Smith, H.M.; Badihi, I. The psychology of control: Effects of control over supplementary light on welfare of marmosets. Appl. Anim. Behav. Sci. 2012, 137, 166-174. [CrossRef]

16. Allard, S.M.; Bashaw, M.J. Empowering Zoo Animals. In Scientific Foundations of Zoos and Aquariums; Amsterdam University Press: Amsterdam, The Netherlands, 2019; pp. 241-273.

17. Duboscq, J.; Romano, V.; Sueur, C.; MacIntosh, A.J.J. Scratch that itch: Revisiting links between self-directed behaviour and parasitological, social and environmental factors in a free-ranging primate. R. Soc. Open Sci. 2016, 3, 160571. [CrossRef]

18. Baker, K.C.; Aureli, F. Behavioural Indicators of Anxiety: An Empirical Test in Chimpanzees. Behaviour 1997, 134, 1031-1050. [CrossRef]

19. Troisi, A. Displacement Activities as a Behavioral Measure of Stress in Nonhuman Primates and Human Subjects. Stress 2002, 5, 47-54. [CrossRef] [PubMed]

20. Whitham, J.C.; Wielebnowski, N. New directions for zoo animal welfare science. Appl. Anim. Behav. Sci. 2013, 147, 247-260. [CrossRef]

21. Weary, D.M.; Fraser, D. Signalling need: Costly signals and animal welfare assessment. Appl. Anim. Behav. Sci. 1995, 44, 159-169. [CrossRef]

22. Sherwen, S.L.; Hemsworth, L.M.; Beausoleil, N.J.; Embury, A.; Mellor, D.J. An Animal Welfare Risk Assessment Process for Zoos. Animals 2018, 8, 130. [CrossRef]

23. Mench, J.A. Assessing animal welfare at the farm and group level: A United States perspective. Anim. Welf. 2003, 12, 493-503.

24. Fleming, P.A.; Wickham, S.L.; Dunston-Clarke, E.J.; Willis, R.S.; Barnes, A.L.; Miller, D.W.; Collins, T. Review of Livestock Welfare Indicators Relevant for the Australian Live Export Industry. Animals 2020, 10, 1236. [CrossRef]

25. Dawkins, M.S. Behaviour as a tool in the assessment of animal welfare. Zoölogy 2003, 106, 383-387. [CrossRef]

26. Broom, D.M. Welfare Assessment and Relevant Ethical Decisions: Key Concepts. Annu. Rev. Biomed. Sci. 2008, 10, T79-T90. [CrossRef] 
27. Barnett, J.; Hemsworth, P. The validity of physiological and behavioural measures of animal welfare. Appl. Anim. Behav. Sci. 1990, 25, 177-187. [CrossRef]

28. Edwards, K.L.; Bansiddhi, P.; Paris, S.; Galloway, M.; Brown, J.L. The development of an immunoassay to measure immunoglobulin A in Asian elephant feces, saliva, urine and serum as a potential biomarker of well-being. Conserv. Physiol. 2019, 7, coy077. [CrossRef]

29. Fraser, D. Assessing animal welfare at the farm and group level: The interplay of science and values. Anim. Welf. 2003, 12, 433-443.

30. Broom, D.M.; Reefmann, N. Chicken welfare as indicated by lesions on carcasses in supermarkets. Br. Poult. Sci. 2005, 46, 407-414. [CrossRef]

31. Fox, M.W. Animal welfare and the dairy industry. J. Dairy Sci. 1983, 66, 2221-2225. [CrossRef]

32. Sørensen, J.T.; Rousing, T.; Møller, S.H.; Bonde, M.; Hegelund, L. On-farm welfare assessment systems: What are the recording costs? Anim. Welf. 2007, 16, 237-239.

33. Brambell, F.W.R. Report of the Technical Committee to Enquire into the Welfare of Animals Kept Under Intensive Livestock Husbandry Systems; Stationery Office: London, UK, 1965.

34. Farner, D.S.; Sircom, G.; Hediger, H. Wild Animals in Captivity, An Outline of the Biology of Zoological Gardens. Bird-Banding 1951, 22. [CrossRef]

35. Veasey, J.S.; Waran, N.K.; Young, R.J. On comparing the behaviour of zoo housed animals with wild conspecifics as a welfare indicator. Anim. Welf. 1996, 5, 13-24.

36. Špinka, M. How important is natural behaviour in animal farming systems? Appl. Anim. Behav. Sci. 2006, 100, 117-128. [CrossRef]

37. Browning, H. The Natural Behavior Debate: Two Conceptions of Animal Welfare. J. Appl. Anim. Welf. Sci. 2019, 23, 325-337. [CrossRef]

38. Finlay, T.; James, L.R.; Maple, T.L. People's Perceptions of Animals. Environ. Behav. 1988, 20, 508-528. [CrossRef]

39. Kutska, D. Variation in visitor perceptions of a polar bear enclosure based on the presence of natural vs. un-natural enrichment items. Zoo Biol. 2009, 28, 292-306. [CrossRef]

40. Melfi, V.; McCormick, W.; Gibbs, A. A preliminary assessment of how zoo visitors evaluate animal welfare according to enclosure style and the expression of behavior. Anthrozoös 2004, 17, 98-108. [CrossRef]

41. McFarland, R.; Barrett, L.; Boner, R.; Freeman, N.J.; Henzi, S.P. Behavioral flexibility of vervet monkeys in response to climatic and social variability. Am. J. Phys. Anthr. 2014, 154, 357-364. [CrossRef]

42. Boyle, S.A.; Smith, A.T. Behavioral modifications in northern bearded saki monkeys (Chiropotes satanas chiropotes) in forest fragments of central Amazonia. Primates 2009, 51, 43-51. [CrossRef] [PubMed]

43. Teichroeb, J.A.; Saj, T.L.; Paterson, J.D.; Sicotte, P. Effect of Group Size on Activity Budgets of Colobus vellerosus in Ghana. Int. J. Primatol. 2003, 24, 743-758. [CrossRef]

44. Howell, C.P.; Cheyne, S.M. Complexities of Using Wild versus Captive Activity Budget Comparisons for Assessing Captive Primate Welfare. J. Appl. Anim. Welf. Sci. 2019, 22, 78-96. [CrossRef] [PubMed]

45. Watters, J.V.; Margulis, S.W.; Atsalis, S. Behavioral monitoring in zoos and aquariums: A tool for guiding husbandry and directing research. Zoo Biol. 2009, 28, 35-48. [CrossRef] [PubMed]

46. Van Der Harst, J.; Fermont, P.; Bilstra, A.; Spruijt, B. Access to enriched housing is rewarding to rats as reflected by their anticipatory behaviour. Anim. Behav. 2003, 66, 493-504. [CrossRef]

47. Jensen, A.-L.M.; Delfour, F.; Carter, T. Anticipatory behavior in captive bottlenose dolphins (Tursiops truncatus): A preliminary study. Zoo Biol. 2013, 32, 436-444. [CrossRef] [PubMed]

48. Vinke, C.; Houx, B.; Bos, R.V.D.; Spruijt, B. Anticipatory behaviour and stereotypical behaviour in farmed mink (Mustela vison) in the presence, absence and after the removal of swimming water. Appl. Anim. Behav. Sci. 2006, 96, 129-142. [CrossRef]

49. Mistlberger, R.E. Circadian food-anticipatory activity: Formal models and physiological mechanisms. Neurosci. Biobehav. Rev. 1994, 18, 171-195. [CrossRef]

50. Makowska, I.J.; Weary, D.M. Differences in Anticipatory Behaviour between Rats (Rattus norvegicus) Housed in Standard versus Semi-Naturalistic Laboratory Environments. PLoS ONE 2016, 11, e0147595. [CrossRef] [PubMed]

51. Clegg, I.L.; Rödel, H.G.; Boivin, X.; Delfour, F. Looking forward to interacting with their caretakers: Dolphins' anticipatory behaviour indicates motivation to participate in specific events. Appl. Anim. Behav. Sci. 2018, 202, 85-93. [CrossRef]

52. Watters, J.V. Searching for behavioral indicators of welfare in zoos: Uncovering anticipatory behavior. Zoo Biol. 2014, 33, 251-256. [CrossRef] [PubMed]

53. Bethell, E.J. A “How-To" Guide for Designing Judgment Bias Studies to Assess Captive Animal Welfare. J. Appl. Anim. Welf. Sci. 2015, 18, S18-S42. [CrossRef]

54. Wichman, A.; Keeling, L.J.; Forkman, B. Cognitive bias and anticipatory behaviour of laying hens housed in basic and enriched pens. Appl. Anim. Behav. Sci. 2012, 140, 62-69. [CrossRef]

55. Richter, S.H.; Schick, A.; Hoyer, C.; Lankisch, K.; Gass, P.; Vollmayr, B. A glass full of optimism: Enrichment effects on cognitive bias in a rat model of depression. Cogn. Affect. Behav. Neurosci. 2012, 12, 527-542. [CrossRef]

56. Roelofs, S.; Boleij, H.; Nordquist, R.E.; van der Staay, F.J. Making Decisions under Ambiguity: Judgment Bias Tasks for Assessing Emotional State in Animals. Front. Behav. Neurosci. 2016, 10, 119. [CrossRef]

57. Spinka, M.; Wemelsfelder, F. Environmental challenge and animal agency. In Animal Welfare; CABI Publishing: Wallingford, UK, 2011; pp. 27-43. 
58. Owen, M.A.; Swaisgood, R.R.; Czekala, N.M.; Lindburg, D.G. Enclosure choice and well-being in giant pandas: Is it all about control? Zoo Biol. 2005, 24, 475-481. [CrossRef]

59. Ross, S.R. Issues of choice and control in the behaviour of a pair of captive polar bears (Ursus maritimus). Behav. Process. 2006, 73, 117-120. [CrossRef] [PubMed]

60. Meehan, C.L.; Mench, J.A. The challenge of challenge: Can problem solving opportunities enhance animal welfare? Appl. Anim. Behav. Sci. 2007, 102, 246-261. [CrossRef]

61. Ward, S.J.; Sherwen, S.; Clark, F.E. Advances in Applied Zoo Animal Welfare Science. J. Appl. Anim. Welf. Sci. 2018, 21, 23-33. [CrossRef]

62. Clark, F. Cognitive enrichment and welfare: Current approaches and future directions. Anim. Behav. Cogn. 2017, 4, 52-71. [CrossRef]

63. Duranton, C.; Horowitz, A. Let me sniff! Nosework induces positive judgment bias in pet dogs. Appl. Anim. Behav. Sci. 2019, 211, 61-66. [CrossRef]

64. Franks, B.; Higgins, E.T. Effectiveness in humans and other animals: A common basis for well-being and welfare. In Advances in Experimental Social Psychology; Olson, J.M., Zanna, M.P., Eds.; Elsevier Academic Press Inc: San Diego, CA, USA, 2012; Volume 46, pp. 285-346.

65. Hopper, L.M.; Egelkamp, C.L.; Fidino, M.; Ross, S.R. An assessment of touchscreens for testing primate food preferences and valuations. Behav. Res. Methods 2019, 51, 639-650. [CrossRef] [PubMed]

66. Dorey, N.R.; Mehrkam, L.R.; Tacey, J. A method to assess relative preference for training and environmental enrichment in captive wolves (Canis lupus and Canis lupus arctos). Zoo Biol. 2015, 34, 513-517. [CrossRef]

67. Dawkins, M. Do hens suffer in battery cages? environmental preferences and welfare. Anim. Behav. 1977, 25, 1034-1046. [CrossRef]

68. Dawkins, M.S. From an animal's point of view: Motivation, fitness, and animal welfare. Behav. Brain Sci. 1990, 13, 1-9. [CrossRef]

69. Burman, O.H.; Parker, R.M.; Paul, E.S.; Mendl, M.T. Anxiety-induced cognitive bias in non-human animals. Physiol. Behav. 2009, 98, 345-350. [CrossRef] [PubMed]

70. Ohl, F.; Arndt, S.S.; van der Staay, F.J. Pathological anxiety in animals. Vet. J. 2008, 175, 18-26. [CrossRef]

71. Fraser, D.; Duncan, I.J. Pleasure, Pain and Animal Welfare: Toward a Natural History of Affect. Anim. Welf. 1998, 7, $383-396$.

72. Panksepp, J. Affective-Social Neuroscience Approaches to Understanding Core Emotional Feelings in Animals. Ment. Health Well-Being Anim. 2008, 57-75. [CrossRef]

73. Landa, L. Pain in domestic animals and how to assess it: A review. Vet. Med. 2012, 57, 185-192. [CrossRef]

74. Rushen, J. Using aversion learning techniques to assess the mental state, suffering, and welfare of farm animals. J. Anim. Sci. 1996, 74, 1990-1995. [CrossRef]

75. Wemelsfelder, F. Animal Boredom: Is a Scientific Study of the Subjective Experiences of Animals Possible? In Advances in Animal Welfare Science 1984; Springer International Publishing: Cham, Switzerland, 1985; pp. 115-154.

76. Mason, G.J.; Burn, C.C. Frustration and boredom in impoverished environments. Anim. Welf. 2018, 114-138. [CrossRef]

77. Meagher, R. Is boredom an animal welfare concern? Anim. Welf. 2019, 28, 21-32. [CrossRef]

78. Bashaw, M.J.; Gibson, M.D.; Schowe, D.M.; Kucher, A.S. Does enrichment improve reptile welfare? Leopard geckos (Eu-blepharis macularius) respond to five types of environmental enrichment. Appl. Anim. Behav. Sci. 2016, 184, 150-160. [CrossRef]

79. Spain, M.; Fuller, G.; Allard, S. Effects of Habitat Modifications on Behavioral Indicators of Welfare for Madagascar Giant Hognose Snakes (Leioheterodon madagascariensis). Anim. Behav. Cogn. 2020, 7, 70-81. [CrossRef]

80. Frézard, A.; Le Pape, G. Contribution to the welfare of captive wolves (Canis lupus lupus): A behavioral comparison of six wolf packs. Zoo Biol. 2003, 22, 33-44. [CrossRef]

81. Shannon, C.E. A mathematical theory of communication. Bell Syst. Tech. J. 1948, 27, 379-423. [CrossRef]

82. Weaver, W. Recent contributions to the mathematical theory of communication. ETC A Rev. Gen. Semant. 1953, 10, $261-281$.

83. Cronin, K.; Ross, S. Technical Contribution: A Cautionary Note on the Use of Behavioural Diversity (H-Index) in Animal Welfare Science. Anim. Welf. 2019, 28, 157-164. [CrossRef]

84. Watters, J.V.; Krebs, B.L.; Pacheco, E. Measuring Welfare through Behavioral Observation and Adjusting It with Dynamic Environments. In Scientific Foundations of Zoos and Aquariums: Their Roles in Conservation and Research; Kaufman, A., Bashaw, M., Maples, T., Eds.; Cambridge University Press: Cambridge, UK, 2018.

85. Platt, J.R. Strong Inference. In Maritime Archaeology; Springer International Publishing: Cham, Switzerland, $1998 ;$ pp. $155-166$.

86. Mentis, M.T. Hypothetico-Deductive and Inductive Approaches in Ecology. Funct. Ecol. 1988, 2, 5-14. [CrossRef]

87. Britten, K.H.; Thatcher, T.D.; Caro, T. Zebras and Biting Flies: Quantitative Analysis of Reflected Light from Zebra Coats in Their Natural Habitat. PLoS ONE 2016, 11, e0154504. [CrossRef] [PubMed]

88. Caro, T. The functions of stotting in Thomson's gazelles: Some tests of the predictions. Anim. Behav. 1986, 34, 663-684. [CrossRef]

89. Clubb, R.; Mason, G.J. Natural behavioural biology as a risk factor in carnivore welfare: How analysing species differences could help zoos improve enclosures. Appl. Anim. Behav. Sci. 2007, 102, 303-328. [CrossRef]

90. Hughes, B.; Duncan, I. The notion of ethological 'need', models of motivation and animal welfare. Anim. Behav. 1988, 36, 1696-1707. [CrossRef]

91. Wemelsfelder, F. The scientific validity of subjective concepts in models of animal welfare. Appl. Anim. Behav. Sci. 1997, 53, 75-88. [CrossRef]

92. Kirkwood, J.K.; Hubrecht, R. Animal Consciousness, Cognition and Welfare. Anim. Welf. 2001, 10, 5-17.

93. Mench, J.A. Thirty Years After Brambell: Whither Animal Welfare Science? J. Appl. Anim. Welf. Sci. 1998, 1, 91-102. [CrossRef] 
94. Broom, D.M. A History of Animal Welfare Science. Acta Biotheor. 2011, 59, 121-137. [CrossRef] [PubMed]

95. Animal and Plant Health Inspection Service. USDA Animal Care: Animal Welfare Act and Animal Welfare Regulations (Blue Book). Available online: www.aphis.usda.gov/animal-welfare/downloads/AC_BlueBook_AWA_508_comp_version.pdf (accessed on 20 February 2021).

96. United States, Congress. Animal Welfare Act (AWA). U.S. Code, 7 U.S.C. Sections 2131-2159. Available online: https://www. animallaw.info/statute/us-awa-animal-welfare-act (accessed on 20 February 2021).

97. The National Science Foundation (NSF). Proposal and Award Policies and Procedures Guide (PAPPG). Available online: https: / / www.nsf.gov / funding/pgm_summ.jsp (accessed on 20 February 2021).

98. Lewandowsky, S.; Ecker, U.K.H.; Seifert, C.M.; Schwarz, N.; Cook, J.T. Misinformation and Its Correction. Psychol. Sci. Public Interes. 2012, 13, 106-131. [CrossRef] [PubMed]

99. Weidenfeld, A.; Williams, A.; Butler, R. Cooperation, Competition, Knowledge Transfer and Innovations among Visitor Attrac-Tions and Their Spatial Proximity and Product Similarity; Final Report; University of Exeter: Exeter, UK, 2011.

100. Mason, G.J.; Latham, N. Can't stop, won't stop: Is stereotypy a reliable animal welfare indicator? Anim. Welf. 2004, 13, S57-S69. 